\title{
Inflammatory Bowel Disease-related Colorectal Cancer in the Asia-Pacific Region: Past, Present, and Future
}

\author{
Wong Zhiqin $^{1}$, Shanthi Palaniappan ${ }^{1}$, Raja Affendi Raja Ali ${ }^{1,2}$ \\ Department of Gastroenterology and Hepatology', Medical Molecular Biology Institute', National University of Malaysia Medical Centre, Kuala \\ Lumpur, Malaysia
}

\begin{abstract}
Patients with inflammatory bowel disease (IBD) are at an increased risk of developing colorectal cancer (CRC), and key contributing factors include chronic colonic inflammation and the extent and duration of disease. This increase in risk is more likely to result from chronic inflammation of the colonic mucosa than from any clearly defined genetic predisposition. However, globally, the true magnitude of this risk is debatable, since results from different studies are heterogeneous in terms of geographical and methodological variables. The prevalence of IBD-related CRC in the Asia-Pacific region ranges from $0.3 \%$ to $1.8 \%$ and a recent study found that the cumulative incidence of IBD-related CRC is comparable to that in Western countries. However, the CRC mortality rate in the Asia-Pacific region is on the rise compared with that in Western countries, and a few Asian countries show particularly rapid upward trends in CRC incidence. Although our understanding of the molecular and clinical basis for IBD-related CRC has improved substantially, our means of prevention, endoscopic surveillance, chemoprevention, and prophylactic surgery remain modest at best. Furthermore, published data on IBD-related CRC in the Asia-Pacific region is lacking, and this review addresses many aspects including epidemiology, natural history, etiopathogenesis, morphology, and biological behaviors of IBD-related CRC and sporadic CRC in the Asia-Pacific region. In this review, we will also discuss the risk factors for CRC in IBD patients, endoscopic technology screening, and surveillance programs and management strategies for IBD-related CRC. (Intest Res 2014;12:194-204)
\end{abstract}

Key Words: Inflammatory bowel disease; Colorectal neoplasms; Asia-Pacific region

\section{INTRODUCTION}

Inflammatory bowel disease (IBD) has traditionally been known as a disease of the West and thought to be rare in the Asia-Pacific region. However, with recent urbanization and modernization of Asian societies, the incidence and prevalence of IBD is now on the rise in many parts of the Asia-Pacific region. Time trend studies from Japan, Korea and Hong Kong have collectively shown an increasing trend in both

Received June 17, 2014. Revised July 1, 2014. Accepted July 1, 2014. Correspondence to Raja Affendi Raja Ali, Consultant Gastroenterologist, Associate Professor \&t Senior Research Fellow, Faculty of Medicine \&t Medical Molecular Biological Institute, National University of Malaysia,Jalan Yaacob Latif, 56000 Cheras, Kuala Lumpur, Malaysia. Tel: +60-3-9145-6094, Fax: +60-3-9145-6692, E-mail: draffendi@ppukm.ukm.edu.my

Financial support: None. Conflict of interest: None.
UC and CD when compared between the 1980-90's and the 2000 's. ${ }^{1-4}$ To date, there have been only few population-based studies conducted in the Asia-Pacific region, the majority of which utilized hospital-based data, which are likely to underestimate the true incidence rates due to patient selection.

Colorectal cancer (CRC) is a well-recognized and serious complication of IBD. Although the CRC incidence in Asian IBD patients was previously thought to be relatively lower than that in Western societies, recent studies have shown a similar incidence. Therefore, as the incidence and prevalence of IBD increases in the Asia-Pacific region the question of whether this increase will be mirrored in CRC rates remains. If so, the difference in the etiopathogenesis of CRC in this population from that in the Western population needs to be clarified. Therefore, this review will focus on IBD-related CRC (IBD-CRC) in the unique multi-cultural Asian population.

๑ Copyright 2014. Korean Association for the Study of Intestinal Diseases. All rights reserved.

This is an Open Access article distributed under the terms of the Creative Commons Attribution Non-Commercial License (http://creativecommons.org/licenses/by-nc/3.0)

which permits unrestricted non-commercial use, distribution, and reproduction in any medium, provided the original work is properly cited. 


\section{EPIDEMIOLOGY AND NATURAL HISTORY OF IBD IN THE ASIA-PACIFIC REGION}

Studies from most countries throughout Asia show a rise in the incidence and prevalence rates of UC and CD. Studies from Hong Kong, Japan, Korea, and India have collectively showed an increasing incidence of IBD. The incidence of UC in these 4 countries has demonstrated an increase from 0.02 cases per 100,000 people per year in 1961 to 6 cases per 100,000 people per year in 2008. ${ }^{1,35-10}$ As for the prevalence of UC, studies from Japan have demonstrated a 3-fold rise between 1991 and 2005, from 18.1 cases per 100,000 people to 63.6 cases per 100,000 people. ${ }^{6,11}$ In Hong Kong, the prevalence of UC has significantly increased from 2.3 to 26.5 cases per 100,000 people from 1997 to $2006 .{ }^{3,8}$ Incidence of CD, although not as high as UC, has also shown an increasing trend over the past few decades. Studies from Hong Kong, Japan, and Korea have collectively demonstrated an increasing incidence from 0.05 to 5.1 cases per 100,000 people per year between 1986 and 2008. ${ }^{1,2,6,79}$ Prevalence of CD in the Asia-Pacific region is also showing an increasing trend, as evidenced by studies from Hong Kong-Republic of China, Japan, and Malaysia-Singapore, where the prevalence rates increased from 1.3 to 2.29 cases, 1.86 to 21.2 cases, and 1.3 to 7.2 cases per 100,000 people, respectively. ${ }^{4,11-14}$ Compared to the West, CD prevalence in the Asia-Pacific region is considered very low, despite the rise in the last decade.

It is well recognized that the rate of UC is much higher than the rate of CD in Asian countries. ${ }^{15}$ However, it is important to note that in Western countries, although UC was more common than $\mathrm{CD}$ a few decades ago, the incidence of
CD has matched and even exceeded that of UC over time. Recent reports from Asia have also indicated a decrease in the ratio of UC and CD over time. ${ }^{16}$

\section{THE STATUS OF CRC IN THE ASIA-PACIFIC REGION}

CRC is one of the major causes of morbidity and mortality worldwide, representing the second most common cancer among females and the third among males. In 2008, annual worldwide incidence of CRC cases was 1.2 million, with an almost equal gender distribution. ${ }^{17}$ Incidence of CRC in the Asia-Pacific region is similar to that in the West, as evidenced by a study in Japan where direct comparison with US populations showed comparable figures in CRC rates. ${ }^{18}$ $\mathrm{CRC}$ in the Asia-Pacific region is on the rise compared to the West. ${ }^{19,20}$ This could be due to wider availability of screening programs and a reduction in smoking among Western men. According to the World Health Organization's (WHO) data, the incidence of CRC in Asia varies among different countries and regions, ${ }^{21,22}$ with China, Japan, Korea and Singapore showing particularly rapid rising trends.

\section{THE AETIO-PATHOGENESIS AND MOLECULAR BASIS OF CRC IN IBD}

The pathogenesis of CRC is a complex and diverse mechanism that involves multiple molecular pathways and factors, including a high fat and low fiber diet, sedentary lifestyle, genetic risk factors, cigarette smoking, alcohol consumption, and obesity. ${ }^{23}$ Patients with long-standing IBD of 8-10 years duration are at risk of CRC or dysplasia. ${ }^{24}$ There is an

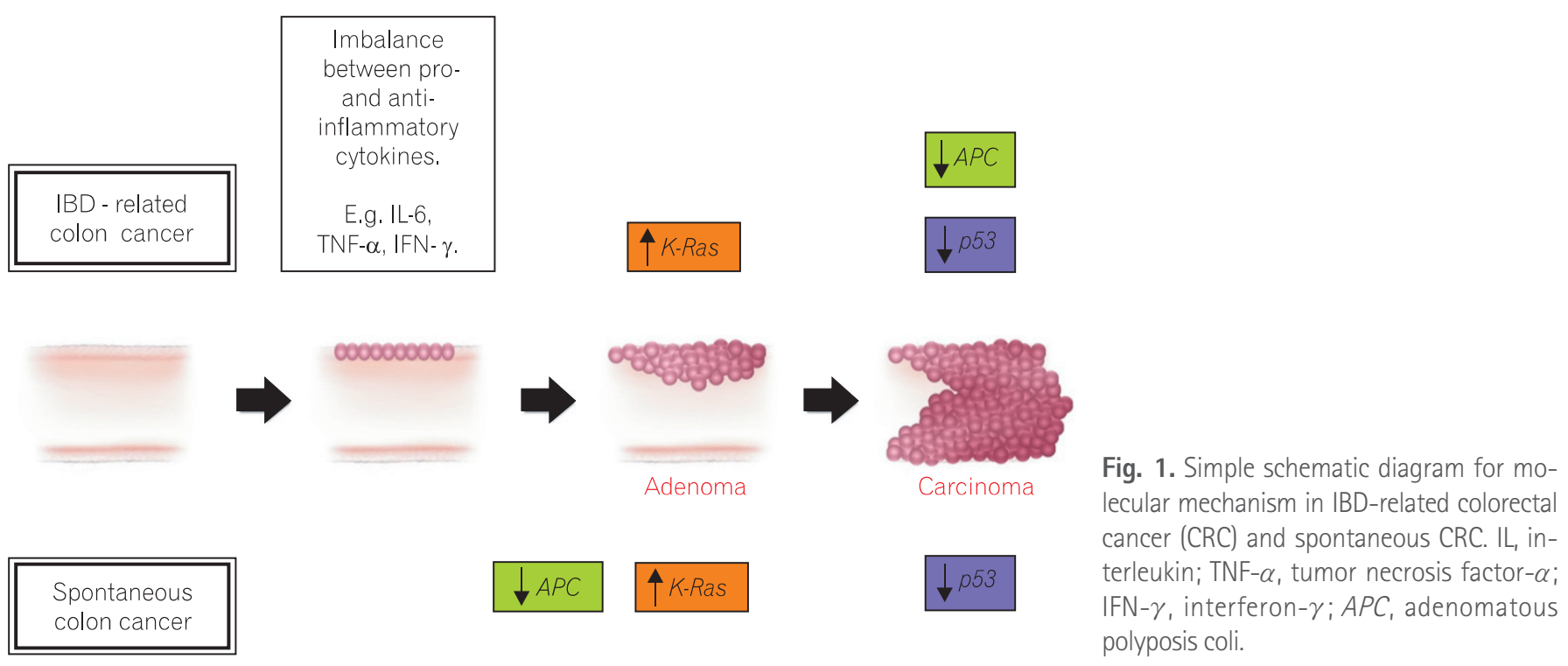


increased production of several inflammatory cytokines by the infiltrating immune cells in the intestinal mucosa of IBD patients. ${ }^{25} \mathrm{UC}$-associated cytokines include interleukins (IL-4, IL-5, IL-6, IL-10) and tumor necrosis factor- $\alpha$, whereas those linked to CD are IL-1 $\beta$, IL-2, IL-6, IL-8, 1L-12, tumor necrosis factor- $\alpha$ and interferon- $\gamma \cdot{ }^{26}$ It is thought that the balance between pro- and anti- inflammatory cytokines plays an important role in the pathogenesis of IBD, and the over production of pro-inflammatory cytokines has been linked to IBD-related carcinogenesis. ${ }^{27}$ The genetic features that lead to sporadic CRC, such as chromosomal instability, microsatellite instability, and DNA hyper-methylation, also occur in IBD-related CRC. Unlike in the normal colonic mucosa, the cells of the inflamed colonic mucosa possess these genetic alterations before there is any histological evidence of dysplasia or cancer. The reason for these abnormalities is not known, but oxidative stress is likely to be involved to some degree. Reactive oxygen and nitrogen species produced by inflammatory cells can affect the regulation of genes that encode factors that prevent carcinogenesis, such as $p 53$, DNA mismatch repair proteins, DNA base excisionrepair proteins, transcription factors, nuclear factor $-\kappa \beta$, and signaling proteins including cyclooxygenases.

Although immune-mediated mechanisms link IBD and CRC, there are similarities between IBD-related CRC and other types of CRC that develop without any signs of overt inflammatory disease. ${ }^{28}$ Some of the essential stages of cancer development, including the formation of aberrant crypt foci, polyps, adenoma, and carcinoma, are similar between non-inflammatory-related CRC and IBD-related CRC. A summary of the molecular mechanism involved in spontaneous CRC and IBD-related CRC is shown in Fig. 1.

\section{THE CLINICAL EPIDEMIOLOGY, PATHOLOGY, AND RISK FACTORS FOR CRC IN IBD EPIDEMIO- LOGY OF UC-RELATED CRC}

Western population studies have shown that the relative risk of UC-related CRC is 0.9-8.3 times higher than that of the normal population, with a prevalence rate of $0.3-1.8 \%{ }^{29.33}$ The prevalence of UC-associated CRC in the Asia-Pacific region ranges between 0.1 and $1.8 \%{ }^{8,34-38} \mathrm{~A}$ multi-center study from China showed that the overall prevalence rate of CRC in patients with UC was $0.87 \%$, and a population-based study from Korea showed a low prevalence rate of just $0.37 \%$. However, the cumulative risks for CRC in both studies were comparable with those in Western countries. ${ }^{29,39,40}$

The only population-based study in the Asia-Pacific region was conducted in Korea. A review of 7,061 cases of UC between 1970 and 2005 found 26 cases of CRC. The cumulative risk of UC-associated CRC in this study was $0.7 \%$ in 10 years, $7.9 \%$ in 20 years, and $33.2 \%$ in 30 years. ${ }^{39,41}$ The comparison of cumulative risk of a few studies conducted in this region is summarized in Table 1.

\section{EPIDEMIOLOGY OF CD-RELATED CRC}

Patients with CD are at a higher risk of developing intestinal malignancy, especially CRC and extraintestinal malignancy, compared to the general population, as shown

Table 1. Cumulative Risk of Colorectal Cancer (CRC) Associated with UC

\begin{tabular}{|c|c|c|c|c|c|c|}
\hline Country & Author (yr) & Study type & $<10-y r$ & $10-y r$ & $20-y r$ & $30-y r$ \\
\hline United Kingdom & Eaden et al. $(2001)^{42}$ & Meta-analysis & -- & 1.6 & 8.3 & 18.4 \\
\hline India & Venkataraman et al. $(2005)^{43}$ & Hospital-based (retrospective) & 0 & 2.3 & 5.8 & -- \\
\hline Japan & Hata et al. $(2003)^{44}$ & Hospital-based & -- & 0.5 & 4.1 & 6.1 \\
\hline China & Gong et al. $(2012)^{40}$ & Hospital-based, multi-center (retrospective) & -- & 1.2 & 3.6 & 14.4 \\
\hline Korea & Kim et al. (2009) & Population-based & -- & 0.7 & 7.9 & 33.2 \\
\hline Taiwan & Wei et al. $(2012)^{45}$ & Hospital-based (retrospective) & -- & 0 & 6.0 & 12.3 \\
\hline
\end{tabular}

Values are presented as \%.

Table 2. Incidence of CD-related Colorectal Cancer (CRC)

\begin{tabular}{cllccc}
\hline Country & \multicolumn{1}{c}{ Author $(\mathbf{y r})$} & Study type & Patients (n) & Person-year at risk & SIR (95\% CI) \\
\hline Japan & Yano et al. (2008) & Hospital based & 512 & 6,213 & $3.2(1.2-6.9)$ \\
Japan & Tsunekazu et al. (2010) & Hospital based & 294 & 4,248 & $5.8(2.13-12.68)$ \\
\hline
\end{tabular}

SIR, standardized incidence ratio. 
by reports from the West. There are limited data available from the Asia-Pacific region (Table 2). A retrospective review of 294 CD cases in Japan over a 20-year period found 13 patients with cancer, of which 6 had CRC, showing higher risk of CRC compared to the general population, with standardized incidence ratio 5.8 (95\% CI=2.13-12.68) ${ }^{46}$ In Japan, the cumulative incidence rate of CD-related CRC was reported as $0.25 \%$ at 10 years, $0.58 \%$ at 15 years, and $0.58 \%$ at 20 years. ${ }^{47}$ The duration of disease, especially more than 20 years, is associated with an increased risk of CRC similar to that reported in Western countries. Studies reported that patients with ileocolitis are particularly more prone to CRC, and in $>80 \%$ of patients diagnosed with CRC, the histological appearance was similar to that of mucinous carcinoma. ${ }^{47}$

\section{PATHOLOGY AND RISK FACTORS}

IBD-associated CRC and sporadic CRC differ in many ways including age at presentation, site of lesions, molecular genetics, and pathological pathways. IBD-associated CRC has an earlier onset, approximately 10-15 years younger than that of sporadic CRC. In UC, the risk of developing CRC begins to increase after 8 years of pancolitis and left-sided colitis. The major differences between sporadic CRC and IBD-associated CRC are summarized in Table 3.

A large population-based study in Korea showed a predominance of females with UC-related CRC, with CRC diagnosis occurring at a mean of 12 years after the initial diagnosis of UC. Diagnosis of CRC in a hospital-based study in Japan was a mean of 18 years after the diagnosis of UC. ${ }^{39,44}$ Another population-based study conducted in Japan identified 169 patients with UC-related CRC with no difference

Table 3. Features of Sporadic Colorectal Cancer (CRC) vs. IBD-related CRC

\begin{tabular}{|c|c|c|}
\hline Variables & Sporadic CRC & IBD-related CRC \\
\hline Age of onset (yr) & $>50$ & $10-15$ yr younger $^{42,48}$ \\
\hline 5 -yr survival rate ${ }^{49}$ & $50 \%$ & $50 \%$ \\
\hline Genetic sequence $^{50-53}$ & Adenoma-carcinoma sequence & Inflammation-dysplasia-carcinoma sequence \\
\hline Sites of lesion & $\begin{array}{l}\text { Commonly left sided in the past, with a recent trend of } \\
\text { right shift as age progresses. }{ }^{54-57}\end{array}$ & Any segment of the diseased colon \\
\hline Morphology of lesion & $\begin{array}{l}\text { Single/multiple lesions } \\
\text { LGD found in raised polypoidal lesions }\end{array}$ & $\begin{array}{l}\text { Mostly has multiple lesions } \\
\text { LGD commonly found in flat lesions }\end{array}$ \\
\hline Pathological features ${ }^{58}$ & Well to moderate differentiated adenocarcinoma & $\begin{array}{l}\text { Higher rates of mucinous/signet ring cell carcinoma compare } \\
\text { to sporadic } C R C\end{array}$ \\
\hline \multirow[t]{4}{*}{ Molecular genetics ${ }^{24,59-62}$} & $\begin{array}{l}\text { Chromosomal instability, microsatellite instability, } \\
\text { hypermethylation. }\end{array}$ & $\begin{array}{l}\text { Chromosomal instability, microsatellite instability, } \\
\text { hypermethylation. }\end{array}$ \\
\hline & $\begin{array}{l}\text { Loss of } A P C \text { gene takes place early and } p 53 \text { mutation } \\
\text { occurs late }\end{array}$ & $\begin{array}{l}A P C \text { and } p 53 \text { mutation in reverse manner compared to } \\
\text { sporadic CRC }\end{array}$ \\
\hline & & Occurs more rapidly may be due to presence of colitis \\
\hline & p53 mutations seen in aggressive lesions & p53 mutations seen within non-dysplastic mucosa \\
\hline
\end{tabular}

LGD, low grade dysplasia; $A P C$, adenomatous polyposis coli.

Table 4. Demographics of Colorectal Cancer (CRC) in UC in the Asia-Pacific Region

\begin{tabular}{|c|c|c|c|c|c|c|c|}
\hline Country & Author (yr) & Study type & Patients (n) & Male (n) & Female (n) & $\begin{array}{c}\text { Mean age at } \\
\text { diagnosis of } U C(y r)\end{array}$ & $\begin{array}{c}\text { Mean age at } \\
\text { diagnosis of } C R C(y r)\end{array}$ \\
\hline Korea & Kim et al. $(2009)^{39}$ & Population-based & 26 & 8 & 18 & $37.9 \pm 17.1$ & $49.6 \pm 14.3$ \\
\hline Hong Kong & Chow et al. $(2009)^{8}$ & Hospital-based & 1 & 1 & 0 & 45.0 & 54.0 \\
\hline \multirow[t]{2}{*}{ Japan } & Watanabe et al. (2011) ${ }^{58}$ & Population-based & 169 & 88 & 81 & -- & 56.8 \\
\hline & Hata et al. $(2003)^{44}$ & Hospital-based & 9 & -- & -- & 28.7 & 46.3 \\
\hline Taiwan & Wei et al. $(2011)^{45}$ & Hospital-based & 6 & 1 & 5 & -- & -- \\
\hline
\end{tabular}


Table 5. Pathological Features of UC Associated Colorectal Cancers (CRC)

\begin{tabular}{lcc}
\hline \multicolumn{1}{c}{ Variables } & $\begin{array}{c}\text { Watanabe et al. } \\
\text { (2011) }\end{array}$ & $\begin{array}{c}\text { Kim et al. } \\
\text { (2009) }\end{array}$ \\
\hline Site of cancer & 24 & 33.4 \\
Right colon & 76 & 63.3 \\
Left colon & & \\
Histology & 75 & 43.4 \\
Well/Moderately differentiated & 6 & 13.3 \\
Poorly differentiated & 17 & 13.3 \\
Mucinous & 2 & 30.0 \\
Others/unknown & & \\
Stage & 38 & 6.7 \\
I & 10 & 20.0 \\
II & 32 & 23.4 \\
III & 21 & 16.7 \\
IV & 0 & 33.3 \\
Unknown & &
\end{tabular}

Values are presented as \%.

between male and female patients and a mean age of 56.8 years at CRC diagnosis. ${ }^{58}$ A nationwide study from Japan and The KASID study from Korea, both studying the characteristics of UC-associated CRC, showed that $2 / 3$ of patients developed left-sided lesions, with a majority showing well to moderately differentiated adenocarcinoma (Table 4 and 5). ${ }^{39,58}$ Watanabe et al. compared sporadic CRC and UCrelated $\mathrm{CRC}$ and found that multiple lesions were present in $11 \%$ of UC-related CRC cases, higher than the $6 \%$ of sporadic CRC cases. Although 75\% of UC-related CRC patients demonstrate well to moderately differentiated adenocarcinoma, the study also reported $17 \%$ of cases with mucinous and signet-ring cell carcinomas, which is significantly higher than the $4 \%$ cases for sporadic CRC. ${ }^{58}$

\section{CRC SURVEILLANCE IN IBD}

\section{Patient Selection for Surveillance Colonoscopy}

The aim of performing a good and timely surveillance program is early detection of lesions so that optimal treatment can be initiated at an early stage, before the development of invasive carcinoma. This results in better prognosis and a reduction in morbidity and mortality. A surveillance program has to be patient and physician friendly to ensure optimal compliance in the follow-up period from the patient, and to be easy monitor by the physician in charge.

A recent study by Lutgens et al. reviewed data from 149 patients taken from the national pathology database in the Netherlands. Twenty-three had undergone colonoscopy surveillance before CRC was finally diagnosed. The 5-year CRCrelated survival rate of patients in the surveillance group was $100 \%$ compared with the $74 \%$ in the non-surveillance group $(P=0.042)$. In the surveillance group, only 1 patient died of CRC compared with the 29 patients in the control group $(P=0.047)$. In addition, more early-stage tumors were found in the surveillance group $(P=0.004)$. This showed that the survival rate is improved if CRC is detected early, at a more favorable stage. ${ }^{63}$ Another study was conducted in Japan, where 217 patients underwent a total of 1,027 surveillance colonoscopies between 1979 and 2001. The 5-year CRCrelated survival rate in the surveillance group was $100 \%$ compared to the $0 \%$ in the non-surveillance group. Moreover, $80 \%$ of the detected CRCs were well to moderately differentiated adenocarcinomas, which are more favorable for treatment with a better prognosis than signet ring cell carcinoma, which was detected in $50 \%$ of patients in the nonsurveillance group. ${ }^{44}$

Duration of disease greatly affects the risk of CRC. The risk of CRC increases 8-10 years after disease onset. ${ }^{42}$ Guidelines from the American Gastroenterology Association (AGA) in 2003 and the European Crohn's and Colitis Organization (ECCO) in 2008 suggested that surveillance colonoscopy should be performed 8-10 years after disease onset in patients with pancolitis and 15 years in patients with left-sided colitis. However, The American College of Gastroenterology (ACG) in 2004 and British Society of Gastroenterology (BSG) in 2010 suggested commencing surveillance at 8-10 years and 10 years after disease onset in patients with pancolitis and left-sided colitis, respectively. ${ }^{64-68}$

CRC surveillance in IBD patients was not mentioned in the Asia-Pacific consensus recommendations for CRC screening. Colonoscopy surveillance is recommended during disease remission, as active inflammation may influence the accuracy of histopathological interpretations. ${ }^{64-68}$ Colonoscopy examination is the preferred mode of investigation over sigmoidoscopy because around $30 \%$ of UC-associated CRC develops in the right side of the colon. ${ }^{69}$

Taken together, the initial surveillance colonoscopy should be performed approximately $8-10$ years after onset of UC pancolitis, left-sided colitis, and Crohn's colitis, involving at least $1 / 3$ of the colon. Patients with ulcerative proctitis do not require surveillance, as there appears to be no increased risk of $\mathrm{CRC}$ in these patients compared with that in the general 
population.

\section{Histopathologic Assessment}

All guidelines mentioned above recommend 4 quadrant biopsies with jumbo forceps at $10 \mathrm{~cm}$ intervals along the colon, with additional targeted biopsies of any suspicious areas. Focus should also be placed on taking 4 quadrant biopsies from the sigmoid and rectum at $5 \mathrm{~cm}$ intervals due to the high risk of cancer development in this region. With this extensive biopsy protocol, obtaining either 33 or 56 biopsies only samples $<1 \%$ of the colonic mucosa. The probability of detecting dysplasia was 90\% in 33 biopsies and 95\% in 56 biopsies. Although the detection rate is high, endoscopy is tedious when obtaining so many biopsies, resulting in inadequate samples being obtained most of the time. ${ }^{70}$ A study from the United States stated that only $54 \%$ of gastroenterologists take 31 biopsy samples ${ }^{71}$ and only $27 \%$ of gastroenterologists in the Netherlands are compliant to the recommendation of 33 biopsy sampling. ${ }^{72}$ This results in ineffective surveillance and under-recognition of dysplasia, leading to delays in management that can potentially lead to increased morbidity and mortality.

\section{What are the Ideal Intervals for Surveillance Colo- socopy?}

All available guidelines on CRC surveillance in patients with IBD recommend continuous surveillance after initial colonoscopy. However, there is no consensus among the guidelines from different regions on the ideal surveillance interval for long-standing IBD patients.

The BSG guidelines divide patients into 3 groups depending on their risk level. Patients who had extensive colitis with no active endoscopic/histological inflammation, left-sided colitis, or Crohn's colitis of $<50 \%$ are considered low risk and colonoscopy screening should be performed at 5 -year intervals. The intermediate risk group will require colonoscopy surveillance at 3-year intervals, and includes those who had extensive colitis with mild active endoscopic/histological inflammation, or post-inflammatory polyps, or a family history of CRC in a first degree relative aged $>50$ years. High risk patients with extensive colitis and moderate/severe active endoscopic/histological inflammation, stricture in the past 5 years declining surgery, primary sclerosing cholangitis (PSC) or who underwent transplant for PSC, or a family history of $\mathrm{CRC}$ in a first-degree relative aged $<50$, will require yearly colonoscopy surveillance. ${ }^{65}$
The ECCO guidelines recommend colonoscopy at 2-year intervals after diagnosis for the first 20 years and once per year thereafter. ${ }^{64}$ The AGA guidelines suggested a more aggressive surveillance colonoscopy interval of every 1-2 years without further stratifying patients into subgroups. ${ }^{68}$

A note on patient diagnosed with PSC: it is recommended in all the guidelines that surveillance colonoscopy is to be performed upon diagnosis and yearly thereafter.

\section{The Management Strategy for IBD-Related CRC: Any Difference from Sporadic CRC?}

A meta-analysis of 10 prospective studies of 1,225 patients showed that the chance of cancer detection during colectomy was $42 \%$ for high-grade dysplasia and $19 \%$ for lowgrade dysplasia. ${ }^{73}$ This is a distinct feature of IBD-CRC. The dysplastic lesion in IBD-related CRC does not follow the typical adenoma-carcinoma sequence as seen in sporadic CRC, in which the identification of adenomatous lesions is easier than the flat lesions in IBD-related CRC. The dysplastic lesions in IBD patients can be polypoidal, flat, localized, or multi-focal, and these flat lesions are difficult to resect endoscopically and often indicate the need for surgical removal of the entire colon and rectum. Thus, the surveillance protocol is critically important in this subset of IBD patients. It is observed that in patients with Stage I and II CRC, there is no significant difference in survival rates between IBDrelated CRC and sporadic CRC. Early detection of dysplastic lesions leads to similar postoperative outcomes in both IBDrelated and sporadic CRC patients.

The only study available in the Asia-Pacific region was conducted by Watanabe et al. in Japan, and showed that the stage III survival rate for UC-related CRC was significantly lower than that for sporadic CRC (43\% vs. $57.4 \%$, $P=0.032$ ) among 169 UC-related CRC and 108,536 sporadic CRC patients. ${ }^{58}$ This result was supported by a large-scale nationwide population-based study in a Western country (Denmark), in which UC-related CRC patients had poorer survival than sporadic CRC patients, with an overall mortality rate ratio of $1.17(95 \% \mathrm{CI}=1.01-1.36){ }^{74}$

If chronic inflammation is the main cause of CRC in patients with IBD, then suppressing inflammation should theoretically lower the risk for IBD-related CRC. However, studies have failed to establish that the anti-inflammatory agents most commonly used to treat IBD have chemopreventive effects against CRC. ${ }^{75}$ In a systematic review, Velayos et al. ${ }^{76}$ concluded that mesalazine has chemopreventive effects against $\mathrm{CRC}$ and dysplasia (OR=0.51), but this study 
used heterogeneous definitions of mesalazine exposure and compared studies with different designs (case-control, retrospective cohort, secondary analyses). Other studies ${ }^{77,78}$ that investigated the effects of inflammation on development of dysplasia and CRC did not observe independent, chemopreventive effects of mesalazine-based agents. Therefore, it is unclear if mesalazine-based therapies prevent colonic dysplasia and CRC.

Thiopurines are another class of anti-inflammatory drugs that are used to treat patients with IBD, but they were not found to protect against colonic dysplasia or CRC. ${ }^{77,79}$ Ursodeoxycholic acid (UDCA), an exogenous bile acid used to treat patients with PSC has also been studied as a chemopreventive agent. Among patients with PSC, a significant difference in the incidence of colonic neoplasia was observed between a group that received $13-15 \mathrm{mg} \cdot \mathrm{kg}^{-1} \cdot$ day $^{-1}$ UDCA (32\% developed cancer) and the untreated group (controls, $72 \%$ developed cancer). ${ }^{80}$ Nevertheless, most patients with PSC are treated with lower doses of UDCA, which may protect against CRC.

\section{The Future of CRC Surveillance}

There has been a trend showing a divergence from random biopsy sampling towards more focused and targeted biopsies to increase the diagnostic yield and improve the efficacy of surveillance. Many new endoscopy technologies are now emerging to further assist endoscopists in increasing the efficiency of dysplasia detection.

Chromoendoscopy involves spraying a dye (indigo carmine or methylene blue) onto the colonic mucosa to allow better visualization and detailed examination of the abnormal mucosa. This method will enhance subtle lesions, which are not seen under white light endoscopy.

A prospective study by Kiesllich et al. in 263 patients showed that chromoendoscopy allowed more targeted biopsies and significantly more intraepithelial neoplasia were detected in the chromoendoscopy group (32 vs. 10, $P=0.003$ ). ${ }^{81}$ Another prospective study by Hurlstone et al. showed a significantly higher detection rate of dysplasia in the chromoendoscopy group than in the conventional endoscopy group, where 69 lesions were identified by chromoendoscopy compared to 24 lesions out of 700 patients enrolled in the study $(P<0.001){ }^{82}$

This is the only technique that is recommended in the BSG 2010 and ECCO 2008 guidelines. The limitation of this technique is that it requires a trained endoscopist to identify the abnormal mucosa, is very time-consuming, and its use in clinical practice may only be limited to specialist IBD centers.

Chromoendoscopy with confocal endomicroscopy is another new technology, where $10 \%$ fluorescein is injected intravenously and real-time histology is interpreted by skilled and trained endoscopists. In a study by Kiesllich with 161 patients, in $<50 \%$ of biopsy samples obtained $(P=0.008)$ using chromoscopy with endomicroscopy, 4.75 -fold more neoplasias could be detected $(P=0.005)$ than with conventional colonoscopy alone. In this study, a total of 5,580 confocal endomicroscopic images from 134 circumscribed lesions were compared with histologic results, and a high correlation of neoplastic changes by endomicroscopy was observed with a sensitivity of $94.7 \%$, specificity of $98.3 \%$, and accuracy of $97.8 \%{ }^{83}$

Narrow band imaging is now widely available, and uses optical fiber technology to provide clearer imaging of the vessels and pit patterns caused by the irregular optical absorption of light by hemoglobin. ${ }^{84}$ Dekker conducted a study in 42 patients with long-standing UC, and examination of narrow band imaging and conventional endoscopy showed comparable results. $^{85}$

Fluorescence endoscopy allows endoscopists to assess intraepithelial neoplasia after topical or systemic sensitization with 5 -aminolevulinic acid. Another technique is optical coherence tomography, which uses an inbuilt optical analogue with endoscopic ultrasonography and allows endoscopists to image as deep as $2 \mathrm{~mm}$. These 2 methods are very new and still in the development phase, and more studies are required with promising data to further support their utility as a routine endoscopy-assisted tool in the future.

\section{CONCLUSIONS}

CRC remains a major threat to patients with long-standing IBD. IBD-related CRC is reported and expected to be on the rise in the Asia-Pacific region, and this may be due to the increasing incidence of IBD in this region. At present, studies on the prevalence and incidence of IBD-related CRC in the Asia-Pacific region are limited. However, based on the limited data from the Asia-Pacific region and increasing evidence from Western countries, we can conclude that patients with long-standing IBD possess an increased risk of developing CRC. Multiple cytokines, oxidative DNA damage, genomic instability, and epigenetic factors have all been implicated in the process of carcinogenesis in IBD patients. The exact molecular mechanisms for all of these processes remain unknown, although advances in molecular medi- 
cine are expected to help unravel these issues. It is observed that IBD-related CRC shares several features with sporadic $\mathrm{CRC}$, including the presence of dysplastic precursor lesions, whether flat or raised, and similar early-stage survival rates and molecular alterations (the frequency and timing of these alterations are different). Although the similarities between IBD-related and sporadic CRC are notable, they differ in several important ways. Patients with IBD-related CRC are diagnosed at a younger age, in the setting of long-standing colonic inflammation, and precursor dysplastic lesions tend to be multi-focal. The clinical consequence of this difference accounts for the different surgical approach in which IBDrelated CRC patients are usually treated with total proctocolectomy, whereas sporadic CRC patients are treated with segmental resection of the affected colon.

Advances in endoscopic technologies should be helpful in improving the detection of dysplasia and hence improving the effectiveness of surveillance programs for CRC in IBD patients. However, further studies are required to assess costeffectiveness, especially in the Asia-Pacific region in which different countries with different financial capabilities use these high-tech and costly endoscopic machines. Chemopreventive agents should be considered, with the exception of UDCA in IBD patients with PSC. However, their efficacy and methods of utility are far from established. In the future, IBD patients should be stratified based on their confirmed risk factors for developing CRC to perform a more personalized CRC surveillance program in terms of the optimal time to begin screening and the appropriate time-interval for screening. Further large-scale, population-based studies are needed in the Asia-Pacific region to address these issues related to IBD and CRC.

\section{REFERENCES}

1. Yang SK, Yun S, Kim JH, et al. Epidemiology of inflammatory bowel disease in the Songpa-Kangdong district, Seoul, Korea, 1986-2005: a KASID study. Inflamm Bowel Dis 2008;14:542549.

2. Yao T, Matsui T, Hiwatashi N. Crohn's disease in Japan: diagnostic criteria and epidemiology. Dis Colon Rectum 2000;43:S85S93.

3. Lok KH, Hung HG, Ng CH, et al. Epidemiology and clinical characteristics of ulcerative colitis in Chinese population: experience from a single center in Hong Kong. J Gastroenterol Hepatol 2008;23:406-410.

4. Thia KT, Luman W, Jin OC. Crohn's disease runs a more aggressive course in young Asian patients. Inflamm Bowel Dis 2006;
12:57-61.

5. Kitahora T, Utsunomiya T, Yokota A. Epidemiological study of ulcerative colitis in Japan: incidence and familial occurrence. The Epidemiology Group of the Research Committee of Inflammatory Bowel Disease in Japan. J Gastroenterol 1995;30(Suppl 8):5-8.

6. Morita N, Toki S, Hirohashi T, et al. Incidence and prevalence of inflammatory bowel disease in Japan: nationwide epidemiological survey during the year 1991. J Gastroenterol 1995;30(Suppl 8):1-4.

7. Leong RW, Lau JY, Sung JJ. The epidemiology and phenotype of Crohn's disease in the Chinese population. Inflamm Bowel Dis 2004;10:646-651.

8. Chow DK, Leong RW, Tsoi KK, et al. Long-term follow-up of ulcerative colitis in the Chinese population. Am J Gastroenterol 2009;104:647-654.

9. Shin DH, Sinn DH, Kim YH, et al. Increasing incidence of inflammatory bowel disease among young men in Korea between 2003 and 2008. Dig Dis Sci 2011;56:1154-1159.

10. Sood A, Midha V, Sood N, Bhatia AS, Avasthi G. Incidence and prevalence of ulcerative colitis in Punjab, North India. Gut 2003; 52:1587-1590.

11. Asakura K, Nishiwaki Y, Inoue N, Hibi T, Watanabe M, Takebayashi T. Prevalence of ulcerative colitis and Crohn's disease in Japan. J Gastroenterol 2009;44:659-665.

12. Higashi A, Watanabe Y, Ozasa K, Hayashi K, Aoike A, Kawai K. Prevalence and mortality of ulcerative colitis and Crohn's disease in Japan. Gastroenterol Jpn 1988;23:521-526.

13. Sung JJ, Hsu RK, Chan FK, Liew CT, Lau JW, Li AK. Crohn's disease in the Chinese population. An experience from Hong Kong. Dis Colon Rectum 1994;37:1307-1309.

14. Zheng JJ, Zhu XS, Huangfu Z, Shi XH, Guo ZR. Prevalence and incidence rates of Crohn's disease in mainland China: a metaanalysis of 55 years of research. J Dig Dis 2010;11:161-166.

15. Ng SC, Tang W, Ching JY, et al. Incidence and phenotype of inflammatory bowel disease based on results from the Asiapacific Crohn's and colitis epidemiology study. Gastroenterology 2013;145:158-165.

16. Thia KT, Loftus EV, Jr., Sandborn WJ, Yang SK. An update on the epidemiology of inflammatory bowel disease in Asia. Am J Gastroenterol 2008;103:3167-3182.

17. Jemal A, Bray F, Center MM, Ferlay J, Ward E, Forman D. Global cancer statistics. CA Cancer J Clin 2011;61:69-90.

18. Yiu HY, Whittemore AS, Shibata A. Increasing colorectal cancer incidence rates in Japan. Int J Cancer 2004;109:777-781.

19. Bae JM, Jung KW, Won YJ. Estimation of cancer deaths in Korea for the upcoming years. J Korean Med Sci 2002;17:611-615.

20. Yang L, Parkin DM, Li L, Chen Y. Time trends in cancer mortal- 
ity in China: 1987-1999. Int J Cancer 2003;106:771-783.

21. Hirabayashi Y, Tanaka S. Comparison of time trends in colorectal cancer incidence (1973-97) in East Asia, Europe and USA, from Cancer Incidence in Five Continents Vol. IV-VIII. Jpn J Clin Oncol 2007;37:325-327.

22. Ferlay J, Shin HR, Bray F, Forman D, Mathers C, Parkin DM. Estimates of worldwide burden of cancer in 2008: GLOBOCAN 2008. Int J Cancer 2010;127:2893-2917.

23. Le Marchand L, Wilkens LR, Hankin JH, Kolonel LN, Lyu LC. A case-control study of diet and colorectal cancer in a multiethnic population in Hawaii (United States): lipids and foods of animal origin. Cancer Causes Control 1997;8:637-648.

24. Xie J, Itzkowitz SH. Cancer in inflammatory bowel disease. World J Gastroenterol 2008;14:378-389.

25. Neurath MF, Fuss I, Schurmann G, et al. Cytokine gene transcription by NF-kappa B family members in patients with inflammatory bowel disease. Ann N Y Acad Sci 1998;859:149159.

26. Shanahan F. Inflammatory bowel disease: immunodiagnostics, immunotherapeutics, and ecotherapeutics. Gastroenterology 2001;120:622-635.

27. Berg DJ, Davidson N, Kuhn R, et al. Enterocolitis and colon cancer in interleukin-10-deficient mice are associated with aberrant cytokine production and CD4(+) TH1-like responses. J Clin Invest 1996;98:1010-1020.

28. Terzic J, Grivennikov S, Karin E, Karin M. Inflammation and colon cancer. Gastroenterology 2010;138:2101-2114.

29. Ekbom A, Helmick C, Zack M, Adami HO. Ulcerative colitis and colorectal cancer. A population-based study. N Engl J Med 1990;323:1228-1233.

30. Gyde SN, Prior P, Allan RN, et al. Colorectal cancer in ulcerative colitis: a cohort study of primary referrals from three centres. Gut 1988;29:206-217.

31. Langholz E, Munkholm P, Davidsen M, Binder V. Colorectal cancer risk and mortality in patients with ulcerative colitis. Gastroenterology 1992;103:1444-1451.

32. Rutegard JN, Ahsgren LR, Janunger KG. Ulcerative colitis. Colorectal cancer risk in an unselected population. Ann Surg 1988;208:721-724.

33. Stonnington CM, Phillips SF, Zinsmeister AR, Melton LJ, 3rd. Prognosis of chronic ulcerative colitis in a community. Gut 1987;28:1261-1266.

34. Park SH, Kim YM, Yang SK, et al. Clinical features and natural history of ulcerative colitis in Korea. Inflamm Bowel Dis 2007; 13:278-283.

35. Wang Y, Ouyang Q. Ulcerative colitis in China: retrospective analysis of 3100 hospitalized patients. J Gastroenterol Hepatol 2007;22:1450-1455.
36. Ling KL, Ooi CJ, Luman W, Cheong WK, Choen FS, Ng HS. Clinical characteristics of ulcerative colitis in Singapore, a multiracial city-state. J Clin Gastroenterol 2002;35:144-148.

37. Jiang L, Xia B, Li J, et al. Retrospective survey of 452 patients with inflammatory bowel disease in Wuhan city, central China. Inflamm Bowel Dis 2006;12:212-217.

38. Kochhar R, Goenka MK, Kaushik SP, Gupta NM, Nagi B, Mehta SK. Colorectal carcinoma in Indian patients with idiopathic ulcerative colitis. Eur J Cancer Prev 1992;1:293-296.

39. Kim BJ, Yang SK, Kim JS, et al. Trends of ulcerative colitis-associated colorectal cancer in Korea: A KASID study. J Gastroenterol Hepatol 2009;24:667-671.

40. Gong W, Lv N, Wang B, et al. Risk of ulcerative colitis-associated colorectal cancer in China: a multi-center retrospective study. Dig Dis Sci 2012;57:503-507.

41. Ooi CJ, Fock KM, Makharia GK, et al. The Asia-Pacific consensus on ulcerative colitis. J Gastroenterol Hepatol 2010;25:453468.

42. Eaden JA, Abrams KR, Mayberry JF. The risk of colorectal cancer in ulcerative colitis: a meta-analysis. Gut 2001;48:526-535.

43. Venkataraman S, Mohan V, Ramakrishna BS, et al. Risk of colorectal cancer in ulcerative colitis in India. J Gastroenterol Hepatol 2005;20:705-709.

44. Hata K, Watanabe T, Kazama S, et al. Earlier surveillance colonoscopy programme improves survival in patients with ulcerative colitis associated colorectal cancer: results of a 23year surveillance programme in the Japanese population. Br J Cancer 2003;89:1232-1236

45. Wei SC, Shieh MJ, Chang MC, Chang YT, Wang CY, Wong JM. Long-term follow-up of ulcerative colitis in Taiwan. J Chin Med Assoc 2012;75:151-155.

46. Mizushima T, Ohno Y, Nakajima K, et al. Malignancy in Crohn's disease: incidence and clinical characteristics in Japan. Digestion 2010;81:265-270.

47. Yano Y, Matsui T, Uno H, Hirai F, Futami K, Iwashita A. Risks and clinical features of colorectal cancer complicating Crohn's disease in Japanese patients. J Gastroenterol Hepatol 2008;23: 1683-1688.

48. Lakatos L, Mester G, Erdelyi Z, et al. Risk factors for ulcerative colitis-associated colorectal cancer in a Hungarian cohort of patients with ulcerative colitis: results of a population-based study. Inflamm Bowel Dis 2006;12:205-211.

49. Rhodes JM, Campbell BJ. Inflammation and colorectal cancer: IBD-associated and sporadic cancer compared. Trends Mol Med 2002;8:10-16.

50. Muto T, Nagawa H, Watanabe T, Masaki T, Sawada T. Colorectal carcinogenesis: historical review. Dis Colon Rectum 1997;40: S80-S85. 
51. Vogelstein B, Fearon ER, Hamilton SR, et al. Genetic alterations during colorectal-tumor development. N Engl J Med 1988;319:525-532.

52. Brentnall TA, Crispin DA, Rabinovitch PS, et al. Mutations in the p53 gene: an early marker of neoplastic progression in ulcerative colitis. Gastroenterology 1994;107:369-378.

53. Watanabe T, Kobunai T, Toda E, et al. Gene expression signature and the prediction of ulcerative colitis-associated colorectal cancer by DNA microarray. Clin Cancer Res 2007;13:415420.

54. Takada H, Ohsawa T, Iwamoto S, et al. Changing site distribution of colorectal cancer in Japan. Dis Colon Rectum 2002;45: 1249-1254.

55. Goh KL, Quek KF, Yeo GT, et al. Colorectal cancer in Asians: a demographic and anatomic survey in Malaysian patients undergoing colonoscopy. Aliment Pharmacol Ther 2005;22:859864.

56. Huang J, Seow A, Shi CY, Lee HP. Colorectal carcinoma among ethnic Chinese in Singapore: trends in incidence rate by anatomic subsite from 1968 to 1992. Cancer 1999;85:2519-2525.

57. Yamaji Y, Mitsushima T, Ikuma H, et al. Right-side shift of colorectal adenomas with aging. Gastrointest Endosc 2006;63: 453-458.

58. Watanabe T, Konishi T, Kishimoto J, Kotake K, Muto T, Sugihara K. Ulcerative colitis-associated colorectal cancer shows a poorer survival than sporadic colorectal cancer: a nationwide Japanese study. Inflamm Bowel Dis 2011;17:802-808.

59. Murthy S, Flanigan A, Clearfield H. Colorectal cancer in inflammatory bowel disease: molecular and clinical features. Gastroenterol Clin North Am 2002;31:551-564.

60. Tahara T, Inoue N, Hisamatsu T, et al. Clinical significance of microsatellite instability in the inflamed mucosa for the prediction of colonic neoplasms in patients with ulcerative colitis. J Gastroenterol Hepatol 2005;20:710-715.

61. van Dieren JM, Wink JC, Vissers KJ, et al. Chromosomal and microsatellite instability of adenocarcinomas and dysplastic lesions (DALM) in ulcerative colitis. Diagn Mol Pathol 2006;15: 216-222.

62. Zisman TL, Rubin DT. Colorectal cancer and dysplasia in inflammatory bowel disease. World J Gastroenterol 2008;14:26622669.

63. Lutgens MW, Oldenburg B, Siersema PD, et al. Colonoscopic surveillance improves survival after colorectal cancer diagnosis in inflammatory bowel disease. Br J Cancer 2009;101:16711675 .

64. Biancone L, Michetti P, Travis S, et al. European evidence-based Consensus on the management of ulcerative colitis: Special situations. J Crohns Colitis 2008;2:63-92.
65. Cairns SR, Scholefield JH, Steele RJ, et al. Guidelines for colorectal cancer screening and surveillance in moderate and high risk groups (update from 2002). Gut 2010;59:666-689.

66. Eaden JA, Mayberry JF. Guidelines for screening and surveillance of asymptomatic colorectal cancer in patients with inflammatory bowel disease. Gut 2002;51(Suppl 5):V10-V12.

67. Kornbluth A, Sachar DB. Ulcerative colitis practice guidelines in adults (update): American College of Gastroenterology, Practice Parameters Committee. Am J Gastroenterol 2004;99:13711385.

68. Winawer S, Fletcher R, Rex D, et al. Colorectal cancer screening and surveillance: clinical guidelines and rationale-Update based on new evidence. Gastroenterology 2003;124:544-560.

69. Connell WR, Lennard-Jones JE, Williams CB, Talbot IC, Price $\mathrm{AB}$, Wilkinson KH. Factors affecting the outcome of endoscopic surveillance for cancer in ulcerative colitis. Gastroenterology 1994;107:934-944.

70. Rubin CE, Haggitt RC, Burmer GC, et al. DNA aneuploidy in colonic biopsies predicts future development of dysplasia in ulcerative colitis. Gastroenterology 1992;103:1611-1620.

71. Rodriguez SA, Eisen GM. Surveillance and management of dysplasia in ulcerative colitis by U.S. gastroenterologists: in truth, a good performance. Gastrointest Endosc 2007;66:1070.

72. van Rijn AF, Fockens P, Siersema PD, Oldenburg B. Adherence to surveillance guidelines for dysplasia and colorectal carcinoma in ulcerative and Crohn's colitis patients in the Netherlands. World J Gastroenterol 2009;15:226-230.

73. Bernstein CN, Shanahan F, Weinstein WM. Are we telling patients the truth about surveillance colonoscopy in ulcerative colitis? Lancet 1994;343:71-74.

74. Jensen AB, Larsen M, Gislum M, et al. Survival after colorectal cancer in patients with ulcerative colitis: a nationwide population-based Danish study. Am J Gastroenterol 2006;101:12831287.

75. Farraye FA, Odze RD, Eaden J, Itzkowitz SH. AGA technical review on the diagnosis and management of colorectal neoplasia in inflammatory bowel disease. Gastroenterology 2010;138:746774 .

76. Velayos FS, Terdiman JP, Walsh JM. Effect of 5-aminosalicylate use on colorectal cancer and dysplasia risk: a systematic review and metaanalysis of observational studies. Am J Gastroenterol 2005;100:1345-1353.

77. Rutter M, Saunders B, Wilkinson K, et al. Severity of inflammation is a risk factor for colorectal neoplasia in ulcerative colitis. Gastroenterology 2004;126:451-459.

78. Ullman T, Croog V, Harpaz N, et al. Progression to colorectal neoplasia in ulcerative colitis: effect of mesalamine. Clin Gastroenterol Hepatol 2008;6:1225-1230. 
79. Matula S, Croog V, Itzkowitz S, et al. Chemoprevention of colorectal neoplasia in ulcerative colitis: the effect of 6-mercaptopurine. Clin Gastroenterol Hepatol 2005;3:1015-1021.

80. Pardi DS, Loftus EV, Jr., Kremers WK, Keach J, Lindor KD. Ursodeoxycholic acid as a chemopreventive agent in patients with ulcerative colitis and primary sclerosing cholangitis. Gastroenterology 2003;124:889-893.

81. Kiesslich R, Fritsch J, Holtmann M, et al. Methylene blue-aided chromoendoscopy for the detection of intraepithelial neoplasia and colon cancer in ulcerative colitis. Gastroenterology 2003;124:880-888.

82. Hurlstone DP, Sanders DS, Lobo AJ, McAlindon ME, Cross SS. Indigo carmine-assisted high-magnification chromoscopic colonoscopy for the detection and characterisation of intraepithelial neoplasia in ulcerative colitis: a prospective evaluation. Endoscopy 2005;37:1186-1192.

83. Kiesslich R, Goetz M, Lammersdorf K, et al. Chromoscopyguided endomicroscopy increases the diagnostic yield of intraepithelial neoplasia in ulcerative colitis. Gastroenterology 2007;132:874-882.

84. Kuznetsov K, Lambert R, Rey JF. Narrow-band imaging: potential and limitations. Endoscopy 2006;38:76-81.

85. Dekker E, van den Broek FJ, Reitsma JB, et al. Narrow-band imaging compared with conventional colonoscopy for the detection of dysplasia in patients with longstanding ulcerative colitis. Endoscopy 2007;39:216-221. 